\title{
Efficacy of Ivermectin against Gastrointestinal Nematodes in Small Ruminants of Unorganized Sector in Haryana
}

\author{
Priyanka*, Sukhdeep Vohra and Satyavir Singh \\ Department of Veterinary Parasitology, College of Veterinary Sciences, \\ Lala Lajpat Rai University of Veterinary \& Animal Science, Hisar, India \\ *Corresponding author
}

\section{A B S T R A C T}

\section{Keywords}

Anthelmintic resistance, Haemonchus contortus, Goat, Ivermectin, Sheep

Article Info

Accepted: 08 January 2020 Available Online: 10 February 2020
A total of 60 animals which include thirty sheep and 30 goats of Charkhi Dadri district, Haryana with egg per gram of more than or equal to 150 were divided into four groups i.e. G1, G2 of goats and S1, S2 of sheep, each of 15 animals. G1 and $\mathrm{S} 1$ was dosed with ivermectin, recommended dose in sheep and double dose in goats. Group G2 and S2 served as untreated control. Faecal egg count on day of treatment $\left(0\right.$ day) and $14^{\text {th }}$ day post treatment were determined by the modified McMaster technique. Results revealed that ivermectin in sheep reduced the faecal egg counts by $87.85 \%$ with upper and lower confidence levels as $94.99 \%$ and $70.51 \%$, respectively indicating moderate resistance. In goats, ivermectin reduced the faecal egg count by $99.58 \%$ with upper and lower confidence levels as $99.90 \%$ and $98.22 \%$, respectively indicating susceptibility. The post-treatment coproculture showed larvae of Haemonchus contortus and Strongyloides sp. Thus, the present study revealed presence of moderate anthelmintic resistance in sheep while effective in goats to ivermectin in unorganized sector in Charkhi Dadri district of Haryana.

\section{Introduction}

Small ruminant sector is an integral part of Indian farming especially in arid, semi-arid and mountainous areas (Kumar and Roy, 2013). Rearing of sheep and goats has been a major source of income especially to the marginal farmers of the country (Pathak and Pal, 2008). On an average, $15 \%$ of households in rural areas rear sheep/goat across the country and around $70 \%$ of these animals are reared by small and marginal farmers and landless labourers, playing a vital role in their nutrition, supplementary income and livelihood security (CSWRI, VISION-2050). It has been seen that the gastrointestinal (GI) helminthic infections are one of the major constraint for profitable sheep and goat husbandry in tropical and subtropical countries including India. These animals are vulnerable to a number of GI helminths that not only undermine their health but also play 
an important role in lowering the overall production (Sanyal, 1996). The degree of parasitism or worm burden greatly depends on the management and hygienic conditions of the area (Singla, 1995). Commonly occurring gastrointestinal parasitic diseases in goats and sheep are haemonchosis, strongyloidosis, oesophagostomosis, bunostomosis and trichostrongylosis. Among the nematodes, Haemonchus contortus is the most important GI nematode. These parasites cause both acute infections having a rapid onset along with high mortality levels and chronic infections, which are commonly subclinical, may lead to insidious and important economic losses (Singla, 1995) via reduction of live weight gain, reduced wool and milk production and poor reproductive performance (Sutherland and Scott, 2010). The problem of GI helminths is severe in tropical countries due to highly favourable environmental conditions for its transmission (Singh et al., 2013). Control of GI parasites is mainly achieved by the use of anthelmintic drugs and it will continue to remain, as there seems to be no other alternative for helminth control in small ruminants (Sanyal, 2004). The development of anthelmintic resistance in GI nematodes of small ruminants is of major concern in developing countries of the world including India. The rate at which resistance to anthelmintics is being reported in India is alarming, as it narrows the choice of alternative anthelmintics.

The present study was envisaged to detect the status of anthelmintic resistance to ivermectin against gastrointestinal nematodes of sheep and goat in Charkhi dadri district of Haryana state using faecal egg count reduction test.

\section{Materials and Methods}

A study was undertaken at unorganized farm of sheep and goats in Charkhi dadri district of Haryana to determine the efficacy of ivermectin against gastrointestinal nematodes using faecal egg count reduction (FECR) test. Thirty sheep and 30 goats at Badhra village in Charkhi dadri district, naturally infected with GI nematodes and having eggs per gram (EPG) of faeces $\geq 150$ counts prior to treatment were selected. The selected animals were ascertained of not been administered any anthelmintic during the previous two months. These animals were identified, weighed, their EPG estimated and divided into four groups of 15 animals each on the basis of EPG counts i.e. G1, G2, S1 and S2. Group G1 and S1 was dosed with ivermectin (Trumectin ${ }^{\circledR}$, Zydus Animal Health Ltd., Ahmedabad) @ 0.2 $\mathrm{mg} / \mathrm{kg}$ b.wt. subcutaneously in sheep (S1) and double dose in goats (G2) (Silvestre et al., 2002). Group G2 and S2 served as untreated control.

Faecal egg count of each animal was ascertained on 0 day and $14^{\text {th }}$ day post treatment (PT), by the modified McMaster technique to an accuracy of one egg counted representing 50 EPG. Pooled faecal cultures at $27 \pm 2^{\circ} \mathrm{C}$ for 7 days were made to recover infective larvae $\left(\mathrm{L}_{3}\right)$, from each group on day 0 and $14^{\text {th }}$ PT. The infective larvae were identified as per criteria of Keith (1953). Faecal egg count reduction percentage and confidence intervals (95\%) were determined following the method of the World Association for the Advancement of Veterinary Parasitology using arithmetic mean egg counts (Coles et al., 1992). Resistance was considered to be present, if the egg count reduction following treatment was less than $95 \%$ and the $95 \%$ confidence limit was less than $90 \%$.

Worm populations were considered as severely resistant when per cent reduction in faecal egg counts was less than $60 \%$ and moderately resistant when faecal egg count was reduced between 60 to $95 \%$. Suspected resistance was considered when either of the 
above mentioned criteria was met. All the recorded data was statistically analyzed by one way ANOVA test (SPSS software version 2.0).

\section{Results and Discussion}

Faecal egg counts (Mean \pm S.E.) on 0 and $14^{\text {th }}$ day post-treatment (PT), percent reduction in faecal egg counts (FECR\%), variance, upper and lower confidence limits $(95 \%)$ of goats and sheep naturally infected with gastrointestinal nematodes and treated with ivermectin at Badhra village in Charkhi dadri district are given in table 1. In goats, ivermectin reduced the faecal egg count by $99.58 \%$ with upper and lower confidence levels as $99.90 \%$ and $98.22 \%$, respectively indicating its susceptibility. The susceptibility of ivermectin has been reported by Kumsa et al., (2010) at Oromia Regional State in Southern Ethiopia, Sheferaw et al., (2013) at Dale district in Southern Ethiopia, Kumar et al., (2017) at Sub-Himalayan region of Northern India and Islam et al., (2018) at Bangladesh.

Results in sheep revealed that ivermectin reduced the faecal egg counts by $87.85 \%$ on $14^{\text {th }}$ day PT with upper and lower confidence levels as $94.99 \%$ and $70.51 \%$, respectively indicating moderate resistance of drug against gastrointestinal nematodes. The resistance of ivermectin has also been reported by many workers viz. Howell et al., (2008) in Southeastern United States, Falzon et al., (2013) at Ontario in Canada, Pena-Espinoza et al., (2014) in Denmark, Sharma et al., (2015) at Hisar and Kumar and Singh (2016) also at Hisar. As this drug has been used infrequently in the flock, so moderate resistance is recorded. Coles et al., (1999) have also reported the development of anthelmintic resistance even when two or three treatments are given annually.
The effect of anthelmintics on different genera of GI nematodes of goats and sheep surveyed at Badhra village, Charkhi Dadri are presented in table 2. Based on faecal culture, larvae identified before treatment ( 0 day) comprised mainly of $H$. contortus, followed by Strongyloides sp., Trichostrongylus spp. and Oesophagostomum spp. in all groups of goats and sheep.

The PT coproculture revealed that only larvae of $H$. contortus were identified in sheep of Charkhi Dadri. The presence of only $H$. contortus larvae was also reported by Vadlejch et al., (2014) in Czech Republic and Suresh (2016) at Hisar. The PT coproculture in goats of Charkhi Dadri revealed the predominance of Strongyloides sp. larvae followed by $H$. contortus. In the present study predominance of Strongyloides sp. larvae might be due to their reinfection in experimental animals due to short prepatent period of Strongyloides sp. (Soulsby, 1982). Identification of larvae in untreated control groups of both goats and sheep on 0 day and $14^{\text {th }}$ day comprised predominantly of $H$. contortus, followed by Strongyloides sp., Trichostrongylus spp. and Oesophagostomum spp.

In conclusion, there is moderate resistance to ivermectin in sheep and no resistance in goats against gastrointestinal nematodes of Charkhi Dadri district, Haryana. The faecal culture of treated animals shows predominance of Haemonchus contortus indicating resistance. The resistant GI nematodes of small ruminants, necessitates implementation of urgent measures to control their propagation. Therefore, animal owners should be advised to avoid unnecessary anthelmintic drug therapies and not to use the same drug for longer duration. The current study emphasizes the need to explore the status of anthelmintic resistance in other region of the state and country. 
Table.1 Response to various anthelmintics in goats and sheep naturally infected with gastrointestinal nematodes at Badhra village, Charkhi Dadri

\begin{tabular}{|c|c|c|c|c|c|c|c|c|c|c|}
\hline \multirow[t]{2}{*}{ Group } & \multirow[t]{2}{*}{ Anthelmintic } & \multirow[t]{2}{*}{$\begin{array}{l}\text { Dose } \\
(\mathrm{mg} / \mathrm{kg})\end{array}$} & \multirow[t]{2}{*}{$\begin{array}{l}\text { No. of } \\
\text { goats treated }\end{array}$} & \multirow[t]{2}{*}{$\begin{array}{l}\text { Route of } \\
\text { administration }\end{array}$} & \multicolumn{2}{|c|}{$\begin{array}{l}\text { Faecal egg counts on days } \\
\text { (Mean } \pm \text { S.E.) }\end{array}$} & \multicolumn{2}{|c|}{$\begin{array}{l}\text { Faecal egg counts reduction } \\
\text { on } 12^{\text {th }} \text { day post treatment }\end{array}$} & \multicolumn{2}{|c|}{$\begin{array}{l}\text { Confidence } \\
\text { limits at } 95 \%\end{array}$} \\
\hline & & & & & 0 & 12 & $\%$ & Variance & Upper & Lower \\
\hline G1 & Ivermectin & 0.4 & 15 & $\mathrm{~S} / \mathrm{C}$ & $2366.67^{\mathrm{a}} \pm 430.58$ & $13.33^{b} \pm 9.09$ & 99.58 & 0.50 & 99.90 & 98.22 \\
\hline G2 & Control & --- & 15 & --- & $2560.00^{\mathrm{a}} \pm 334.49$ & $3173.33^{\mathrm{a}} \pm 556.13$ & 0 & --- & --- & --- \\
\hline S1 & Ivermectin & 0.2 & 15 & $\mathrm{~S} / \mathrm{C}$ & $2766.67^{a} \pm 456.97$ & $260.00^{b} \pm 111.61$ & 87.85 & 0.19 & 94.99 & 70.51 \\
\hline $\mathbf{S 2}$ & Control & --- & 15 & --- & $2360.00^{\mathrm{a}} \pm 120.63$ & $2140.00^{\mathrm{a}} \pm 120.63$ & 0 & --- & --- & --- \\
\hline
\end{tabular}

Means with same superscripts in column are not significantly different $(\mathrm{p}<0.05)$

Table.2 Anthelmintic effect on different genera of gastrointestinal nematodes of goats and sheep at Badhra village, Charkhi Dadri

\begin{tabular}{|c|c|c|c|c|c|}
\hline \multirow[t]{3}{*}{ Group } & \multirow[t]{3}{*}{ Species } & \multirow{2}{*}{\multicolumn{2}{|c|}{$\begin{array}{c}\text { Goat } \\
\text { Per cent larval } \\
\text { composition on day }\end{array}$}} & \multirow{2}{*}{\multicolumn{2}{|c|}{$\begin{array}{c}\text { Sheep } \\
\text { Per cent larval } \\
\text { composition on day }\end{array}$}} \\
\hline & & & & & \\
\hline & & $\mathbf{0}$ & 14 & $\mathbf{0}$ & 14 \\
\hline \multirow[t]{4}{*}{ Ivermectin treated } & Haemonchus spp. & 86 & 35 & 88 & 100 \\
\hline & Trichostrongylus spp. & 5 & 0 & 4 & 0 \\
\hline & Oesophagostomum spp. & 1 & 0 & 2 & 0 \\
\hline & Strongyloides sp. & 8 & 65 & 6 & 0 \\
\hline \multirow[t]{4}{*}{ Untreated Control } & Haemonchus spp. & 86 & 87 & 89 & 89 \\
\hline & Trichostrongylus spp. & 6 & 6 & 5 & 4 \\
\hline & Oesophagostomum spp. & 1 & 1 & 1 & 1 \\
\hline & Strongyloides sp. & 7 & 6 & 5 & 6 \\
\hline
\end{tabular}




\section{References}

Coles, G.C., Baur, C., Borgsteede. F.H.M., Geerts, S., Klei, T.R., Taylor, M.A. and Waller, P.J. 1992. World Association for Advancement of Veterinary Parasitology (W.A.A.V.P.): Methods for detection of anthelmintics resistance in nematodes of Veterinary importance. Veterinary Parasitology, 44: 35-44.

CSWRI, Vision-2050 2015. ICAR Central Sheep and Wool Research Institute Avikanagar.

Coles, G. C. 1999. Anthelmintic resistance and the control of worms. Journal of Medical. Microbiology, 48: 323-325.

Falzon, L. C., Menzies, P.I., Vanleeuwen, J., Jones bitton, A., Shakya, K. P., Avula, J., Jansen, J. T. and Peregrine, A.S. 2013. A survey of farm management practices and their associations with anthelmintic resistance in sheep flocks in Ontario, Canada. Small Ruminant Research, 114(1): 41- 45.

Howell, S.B., Burke, J.M., Miller, J.E., Terrill, T.H., Valencia, E., Williams, M.J., Williamson, L.H., Zajac, A.M., Kaplan, R.M. 2008. Prevalence of anthelmintic resistance on sheep and goat farms in the south eastern United States. Journal of American Veterinary Medical Association, 233(12): 19131919.

Islam, S., Dey, A.R., Akter, S., Biswas, H., Talukder, M.H and Alam, M.Z. 2018. Status of anthelmintic resistance of gastrointestinal nematodes in organized sheep and goat farms. Asian Journal of Medical and Biological Research, 4 (4): 378-382.

Kumar, R.R., Yadav, C.L. and Vatsya, S. 2017. Emergence of anthelmintic resistance in Haemonchus contortus on organized sheep and goat farms of SubHimalayan region of Northern India. International Journal of Current
Microbiology and Applied Sciences, 6(10): 790-796.

Kumar, S. and Roy, M.M. 2013. "Small Ruminant's Role in Sustaining Rural Livelihoods in Arid and Semiarid Regions and their Potential for Commercialization". New Paradigms in livestock production from traditional to commercial farming and beyond. Agrotech publishing academy, Udaipur, pp. 57-80.

Kumar, S. and Singh, S. 2016. Detection of multiple anthelmintic resistance against gastrointestinal nematodes in sheep on Central Sheep Breeding Farm, Hisar. Haryana Veterinarian, 55(2): 210-213.

Kumsa, B., Debela, E. and Megersa, B. 2010. Comparative efficacy of albendazole, tetramisole, ivermectin against gastrointestinal nematodes in naturally infected goats in Ziway, Oromia Regional State (Southern Ethiopia). Journal of Animal and Veterinary Advances, 9: 2905-2911.

Keith, R.K. 1953. The differentiation of the infective larvae of some common nematode of cattle. Australian Journal of Zoology, 1: 233-235.

Pathak, A. K. and Pal, S. 2008. Seasonal prevalence of gastrointestinal parasites in goats from Durg district of Haemonchus infection in goats. Veterinary World. 5: 136-137.

Pena-Espinoza, B.M., Stig, M., Thamsborgb, Demelerc, J. and Enemarka, H. L. 2014. Field efficacy of four anthelmintics and confirmation of drug-resistant nematodes by controlled efficacy test and pyrosequencing on a sheep and goat farm in Denmark. Veterinary Parasitology, 206: 208-215.

Sanyal, P.K. 1996. Gastrointestinal parasites and small ruminant production in India. In: Lejambre LF, Knox MR (eds) Sustainable parasite control in small ruminants. ACIAR Proceeding. 74: 
109-112.

Sanyal, P. K. 2004. Road leading to the future of anthelmintic therapy: No longer a bed of Red Roses. In: XV Annual Congress of IAAVP and National Symposium on Application of Molecular Biology in Parasitic Diseases for Rural Development, Pantnagar, pp. 65-71.

Sharma, R., Singh, S. and Vohra, S. 2015. Detection of anthelmintic resistance in gastrointestinal nematodes of sheep on government sheep breeding farm Hisar. Haryana Veterinarian, 54(2): 147-149.

Sheferaw, D., Getachew, D., Bekele, J. and Denbarga, Y. 2013. Assessment of anthelmintic resistance in gastrointestinal nematodes of small ruminants, Dale district, Southern Ethiopia. Journal of Veterinary Medicine and Animal Health, 5(9): 257261.

Singh, V., Varshney, P., Dash, S. K. and Lal, H. P. 2013. Prevalence of gastrointestinal parasites in sheep and goats in and around Mathura, India. Veterinary World, 6(5): 260-262.

Singla, L.D. 1995. A note on sub-clinical gastro-intestinal parasitism in sheep and goats in Ludhiana and Faridkot districts of Punjab. Indian Veterinary Medical
Journal, 19: 61-62.

Soulsby, E.J.L. 1982. Text Book of Veterinary Clinical Parasitology, Vol. I. Helminths. $1^{\text {st }}$ edn. Blackwell Scientific Publications, Oxford.

Silvestre, A., Leignel, V., Berrag, B., Gasnier, N., Humbert, J.F., Chartier, C. and Cabaret, J. 2002. Sheep and goat nematode resistance to anthelmintics: pro and cons among breeding management factors. Veterinary Research, 33: 465-480.

Suresh 2016. Status of anthelmintic resistance on a sheep farm and molecular studies of Haemonchus contortus for detection of benzimidazole resistance. M.V.Sc. Thesis, Lala Lajpat Rai University of Veterinary and Animal Science, Hisar.

Sutherland, I. and Scott, I. 2010. Gastrointestinal nematodes of sheep and cattle: Biology and Control. John Wiley and Sons Ltd., West Sussex, UK. Pp 1160.

Vadlejch, J., Kopecky, O., Kudrnacova, M., Cadkova, Z., Jankovska, I. and Langrova, I. 2014. The effect of risk factors of sheep flock management practices on the development of anthelmintic resistance in the Czech Republic. Small Ruminant Research, 117: 183-190.

\section{How to cite this article:}

Priyanka, Sukhdeep Vohra and Satyavir Singh. 2020. Efficacy of Ivermectin against Gastrointestinal Nematodes in Small Ruminants of Unorganized Sector in Haryana. Int.J.Curr.Microbiol.App.Sci. 9(02): 1645-1650. doi: https://doi.org/10.20546/ijcmas.2020.902.189 